\title{
Comparing the Effects of Reflexology and Footbath on Sleep Quality in the Elderly: A Controlled Clinical Trial
}

\author{
Leila Valizadeh, ${ }^{1}$ Alehe Seyyedrasooli, ${ }^{1}$ Vahid Zamanazadeh, ${ }^{1}$ and Khadijeh Nasiri," \\ ${ }^{1}$ Department of Medical-Surgical Nursing, Faculty of Nursing and Midwifery, Tabriz University of Medical Sciences, Tabriz, IR Iran \\ ${ }^{*}$ Corresponding Author: Khadijeh Nasiri, Department of Medical- Surgical Nursing, Faculty of Nursing and Midwifery, Tabriz University of Medical Sciences, Tabriz, IR Iran. Tel: \\ +98-9372681253, Fax:+98-4524234042, E-mail: Khadije.nasiri@yahoo.com
}

Received 2014 May 22; Revised 2014 September 7; Accepted 2015 March 29.

\begin{abstract}
Background: Sleep disorders are common mental disorders reported among the elderly in all countries, and with nonpharmacological interventions, they could be helped to improve their sleep quality.

Objectives: The aim of this study was to compare the effects of two interventions, foot reflexology and foot bath, on sleep quality in elderly people.

Patients and Methods: This three-group randomized clinical trial (two experimental groups and a control group) was conducted on 69 elderly men. The two experimental groups had reflexology $(n=23)$ and foot bath $(n=23)$ interventions for 6 weeks. The reflexology intervention was done in the mornings, once a week for ten minutes on each foot. The participants in the foot bath group were asked to soak their feet in $41^{\circ} \mathrm{C}$ to $42^{\circ} \mathrm{C}$ water one hour before sleeping. The pittsburgh sleep quality index (PSQI) was completed before and after the intervention through an interview process.

Results: The results showed that the PSQI scores after intervention compared to before it in the reflexology and foot bath groups were statistically significant $(P=0.01, P=0.001)$; however, in the control group did not show a statistically significant difference $(P=0.14)$. In addition, the total score changes among the three groups were statistically significant $(\mathrm{P}=0.01)$. Comparing the score changes of quality of sleep between the reflexology and foot bath groups showed that there was no significant difference in none of the components and the total score $(\mathrm{P}=0.09)$. The two interventions had the same impact on the quality of sleep.

Conclusions: It is suggested that the training of nonpharmacological methods to improve sleep quality such as reflexology and foot bath be included in the elderly health programs. In addition, it is recommended that the impact of these interventions on subjective sleep quality using polysomnographic recordings be explored in future research.
\end{abstract}

Keywords: Bath, Elderly, Reflexology, Sleep

\section{Background}

The world's population is aging. Studies in 2000 showed that world's elderly population was about $13 \%$ and forecasts for 2040 is about $20 \%$ of the world's population (1). Rapid demographic changes in developing countries are more observed (2). Iranian elderly population in 2007 was $7.2 \%$ and reached $8.2 \%$ in 2012 (3).

Sleep is a vital physiological process (4). It is one of the factors that has important role in human health (5), and a major factor in reducing mortality (6).

Sleep disorders and depression are the most common mental disorders reported among the elderly in all countries (7). The most common sleep complaints in the elderly are trouble falling asleep, waking up during the night, waking up early in the morning, and daytime sleepiness (8). Eser et al. showed that $60.9 \%$ of the elderly have insufficient sleep (9). Based on studies conducted in Iran, $67 \%$ of the elderly have sleeping disorders and $61 \%$ have insomnia (10).
Several studies showed that lack of sleep among elderly populations is associated with adverse consequences such as accidents, falls, decrease in cognitive activity, decrease in matters related to self-health care, poor health status, reduced quality of life, and ultimately increased mortality; also increased levels of anxiety and napping during the day are associated with poor sleep $(4,7,11)$. The most common way to treat or deal with sleep problems is to use drugs. Effectiveness of treatment methods without the use of drugs is slower than using hypnotic drugs, but they have more durability and do not have dangerous side effects of drugs such as getting addicted to them (12).

Reflexology is a special compression technique by applying pressure on reflex points on the feet, and each point is responsible for a specific part of the body (13). Given that the nurses, as a member of the health team, have an important management role in the management

Copyright ( 2015, Iranian Red Crescent Medical Journal. This is an open-access article distributed under the terms of the Creative Commons Attribution-NonCommercial 4.0 International License (http://creativecommons.org/licenses/by-nc/4.0/) which permits copy and redistribute the material just in noncommercial usages, provided the original work is properly cited. 
of sleep problems, reflexology as a substitute for medical care can be included in the nurses' activities (14).

There is a relationship between the circadian rhythm of the skin temperature, core body temperature, and sleep cycle with awakening regarding function. Rectal temperature begins to rise in the morning after waking up and reaches its highest point (peak) in the afternoon or evening. Between the core body temperature and sleep tendency, there is a negative relationship; at the beginning of sleep, when the core body temperature significantly reduces, it is more likely to occur. Reduce in body core temperature (rectal) before and during sleep is associated with peripheral vasodilatation and possible heat loss from the body core to the peripheral parts of the body. Therefore, a Footbath with warm water may increase blood flow and ambient temperature, with no increase or decrease in core temperature; and thereby could facilitate the onset of sleep and improve sleep quality $(15,16)$.

Yeung et al. systematically reviewed five studies on the impact of reflexology on sleep as compared with other interventions such as routine care, alprazolam, acupressure, hypnosis, and music (17). However, there is no study that compared the effects of reflexology and Footbath on sleep quality.

\section{Objectives}

The purpose of this study was to compare the effects of reflexology and Footbath on sleep quality of the elderly. The hypotheses were as "sleep quality in three groups (reflexology, foot bath and control) is different", "sleep quality is different between reflexology and foot bath".

\section{Patients and Methods}

'controlled single-blinded parallel trial study conducted in the first half of the year 2013 in Tabriz City, Iran. The person collecting the data was not responsible for the interventions. After getting permission from the ethics committee of Tabriz University of Medical Sciences (Registration number in IRCT: IRCT201210046918N13), the researchers visited the Monempour healthcare center, the only governmental and referral health center in Tabriz, where health care was performed monthly and registered in health care records. This center covered 200 male elderly.

The study was performed using 2 intervention (reflexology and foot bath) groups and one control group. The inclusion criteria included having a relative independence in performing daily activities, no night shifts, being healthy in all aspects of tactile, temperature, hearing, and vision, and having mental health based on health records available in the healthcare center.

The exclusion criteria included having enuresis, starting to use other complementary treatments except hypnotic drugs (which included questions on sleep quality index), and having diabetes for more than 10 years.

Selecting the subjects from one center helped us to eliminate or control some of the confounding factors affected sleep, such as education (most of the elderly in this area had university education), income levels, and health knowledge. In addition, by choosing male elderly and male research assistant for the reflexology intervention, the gender variable was controlled.

To determine the sample size, a preliminary study on 12 elderly in Monempour healthcare center who had health program was conducted. Considering $\alpha=0.05$, and power $=0.9$, the mean and standard deviation difference before and after intervention was $0.75 \pm 0.95$ in the reflexology group, $3.25 \pm 2.98$ in the foot bath group, and $-0.25 \pm 1.7$ in the control group; therefore, the sample size for each group was estimated 20 people. Considering the loss of $20 \%$ of the subjects, 25 people were determined for each group. Subjects for the intervention and control groups were selected using the simple random sampling. In total, using male elderly list of the center, 75 subjects were selected to enter the study. Of the 75 people who were selected for the study, 2 people were not willing to participate in the study and 4 cases had diabetes for more than ten years (exclusion criteria) and thus 6 cases were excluded from the study. Finally, the study continued with 69 subjects. Clinical flowchart is shown in Figure 1.

The researchers called the elderlies of each group separately. During the first meeting, the aim of the study was explained to the participants. After getting an informed consent, the pittsburgh sleep quality index (PSQI) was completed by the researcher assistance. During subsequent meetings the researcher called the participants and informed them. The reflexology intervention was conducted by the researcher assistant who had a certificate of participating in reflexology classes and had formerly been trained for three weeks in one of the center's room equipped with a bed. The person in charge of the intervention was present at the health center from 8 am to $13 \mathrm{pm}$ and carried out the intervention. The intervention sessions were performed for 6 weeks, once a week for 10 minutes with olive oil on each foot. The massage included 5 minutes of full foot massage and 5 minutes of the pineal gland on the big toe massage. Massage was slow with regular rhythm, and within the patients' tolerance (18).

The foot bath was taught to the participants in one session, and in the same session, the participants were asked to perform soaking the foot and measuring the water temperature in the presence of the researcher, while the researcher supervised their performance. For foot bath, the participants were asked to place their foot in a plastic container with the height of $10 \mathrm{~cm}$ similar to the one provided by the researcher filled with warm water of $41^{\circ} \mathrm{C}$ to $42^{\circ} \mathrm{C}$, for 6 weeks, every night for 20 minutes, one hour before their sleeping time. The temperature of the water was measured using a thermometer that was marked on the desired temperature by the researcher. At the end of each week, the participants' performances were followedup by the researcher's phone call. 


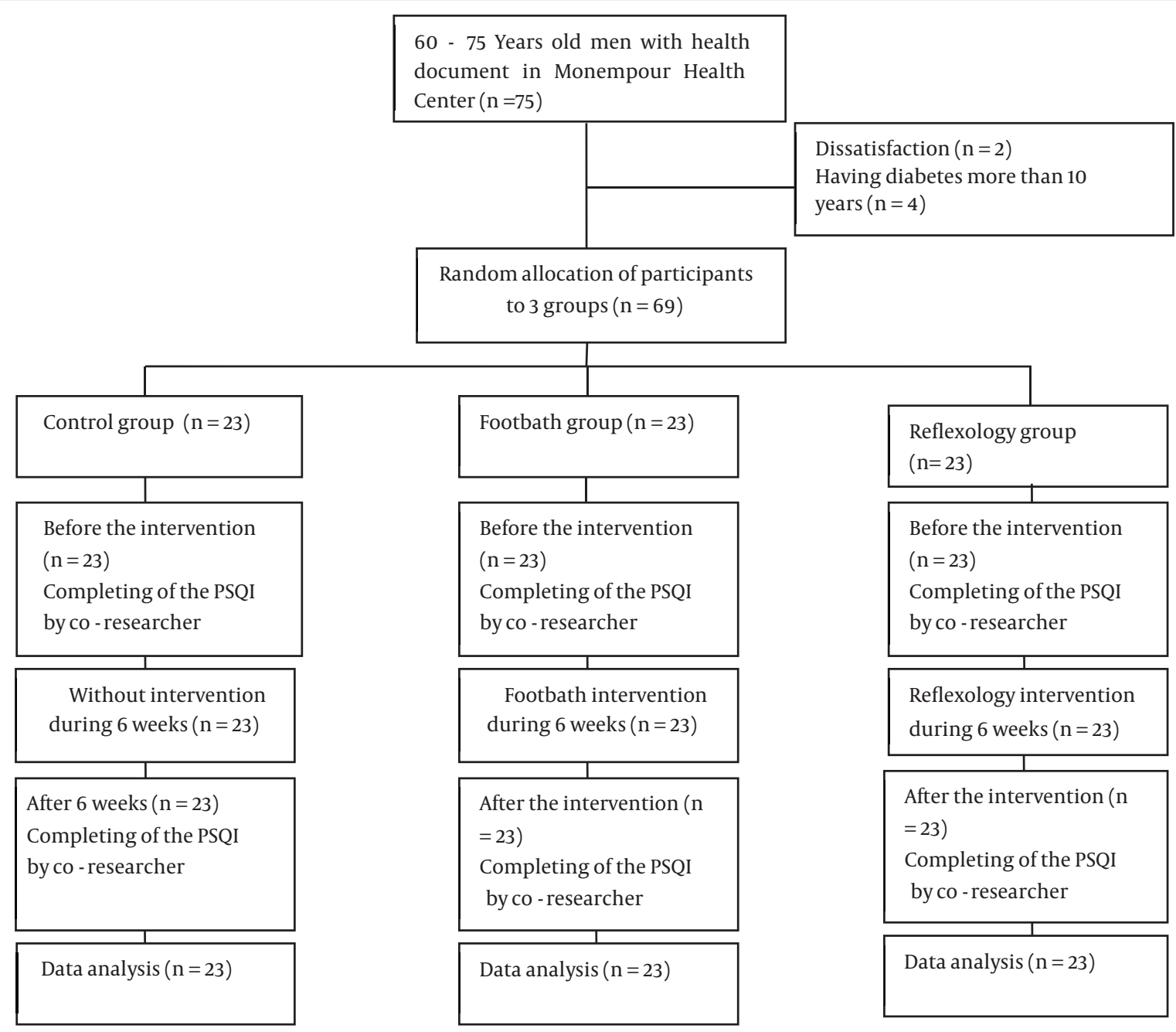

Figure 1. Sampling and Intervention

Subjects in the control group received no intervention. Pittsburgh sleep quality questionnaire was completed for all the three groups at the end of the intervention week by the researcher's assistance.

Data collection tool was a two-part questionnaire that the first part included demographic and social information of the elderly, and the second part included the standard PSQI that measures the quality of sleep and sleep patterns of the elderly. This questionnaire was conducted by Buysse et al. for measuring sleep quality (19). It contains 18 items and is composed of the following seven parts: the subjective sleep quality, sleep latency, sleep duration, sleep efficiency, sleep disturbance, use of sleep medications, and day time dysfunction. Each question scored 0 to 3 , and the maximum score for each part was 3. The total mean score of the seven components made up the tool, which ranged from 0 to 21. The higher the score, the lower was the sleep quality, scores greater than 5 indicated poor sleep quality.

Persian version of the PSQI questionnaire was used in this study. To obtain the validity of the research tool, Persian and English versions were handed to 10 professors of Tabriz University of Medical Sciences with information about the aim of the study; they did necessary modifications, including editing of the seventh sentence of the questionnaire. The validity of the PSQI (Cronbach's alpha) in Agargun et al. study in Turkey was reported 0.8 with the test-retest reliability of 0.93-0.98 (20). In Iran, the reliability of this tool in Hossein Abadi et al. clinical trial study on sleep quality in elderly people, was reported with a Cronbach's alpha of 0.88 (21). In the present study, the reliability of the tool (Cronbach's alpha) with 12 male participants was measured 0.8. Data were analyzed with SPSS version 13 (SPSS Inc., Chicago, Illinois, USA).

The sleep quality score was determined by use of mean descriptive index, standard deviation, frequency, and frequency percentage. First, normality of data was investigated using the Kolmogorov-Smirnov test. parametric conditions were not met and nonparametric tests were used. Then, the sleep quality scores were compared 
before and after the intervention using the Wilcoxon test. Moreover, for comparison of the three groups the Kruskal-Wallis statistical test, for comparison of the two groups (reflexology and foot bath) the Man-Whitney test and for comparison of the sleep pattern in three groups the chi-square was used. Also, for similarity background variables of the three groups, the Kruskal-Wallis test was used. A P value $<0.05$ was considered statistically significant.

\section{Results}

The study included 69 elderly participants. Mean age (standard deviation) of the participants was $66.95 \pm 4.24$ years. Seven percent (7.5\%) of the participants were illiterate and $92.5 \%$ were literate.
Personal and social information of the elderly in each three groups are given in Table 1 . There were no significant differences between the three groups in terms of age, education, and socioeconomic status.

All participants were married and lived with their spouse; none of the participants had problems such as excessive light and noise in their bedroom; and none of the participants reported using medical mattress and pillow.

To assess the quality of sleep, the seven components of PSQI and the total score obtained from the questionnaires were analyzed. The Wilcoxon test showed that the PSQI score after the intervention compared to before it in the reflexology and foot bath groups had a statistically significant decrease (Tables 2 and 3). Sleep quality scores before and after the intervention in the control group did not show a statistically significant difference (Table 4).

\begin{tabular}{|c|c|c|c|c|}
\hline \multirow[t]{2}{*}{ Variables } & \multicolumn{3}{|c|}{ Groups } & \multirow[t]{2}{*}{ Statistical Indicators } \\
\hline & Reflexologyb & Footbath $^{b}$ & Control $^{b}$ & \\
\hline Education & & & & chi-square $=2.96, \mathrm{df}=2, \mathrm{P}=0.22$ \\
\hline Illiterate & $2(8.7)$ & $3(13)$ & $0(0)$ & \\
\hline Elementary & $4(17.4)$ & $2(8.7)$ & $3(13)$ & \\
\hline Guidance School & $0(0)$ & $1(4.3)$ & $3(13)$ & \\
\hline Diploma & $3(13)$ & $9(39.1)$ & $8(34.8)$ & \\
\hline Post Diploma & $2(8.7)$ & $5(21.7)$ & $2(8.7)$ & \\
\hline Bachelor Degree & $9(39.1)$ & $3(13)$ & $3(13)$ & \\
\hline Master's Degree & $3(13)$ & $0(0)$ & $4(17.4)$ & \\
\hline Economic Status & & & & chi-square $=0.89, \mathrm{df}=2, \mathrm{P}=0.69$ \\
\hline Equal Income and Expense & $12(52.2)$ & $11(47.8)$ & $11(47.8)$ & \\
\hline Income More Than Expense & $4(17.4)$ & $0(0)$ & $1(4.3)$ & \\
\hline Income Less Than Expense & $7(30.4)$ & $12(52.2)$ & $11(47.8)$ & \\
\hline $\operatorname{Age}^{c}, y$ & $66.82 \pm 4.8$ & $67.69 \pm 4.28$ & $66.82 \pm 3.84$ & chi-square $=0.66, \mathrm{df}=2, \mathrm{P}=0.71$ \\
\hline
\end{tabular}

Table 2. Mean Scores Before and After the Intervention, and Confidence Interval Changes in Sleep Quality of the Elderly in Reflexology Group ${ }^{a}$

\begin{tabular}{lccccc}
\hline Components of Questionnaire & Before Intervention & & After Intervention & \multicolumn{2}{c}{ Statistical Indicators } \\
\cline { 2 - 6 } & Mean \pm SD & Median & Mean \pm SD & CI 95\% for Difference & P Wilcoxon \\
\hline Subjective Sleep Quality & $0.91 \pm 1.04$ & 1 & $0.52 \pm 0.66$ & $0.04-0.05$ & $\mathrm{Z}=-2.17, \mathrm{P}=0.02$ \\
Sleep latency & $1.17 \pm 1.15$ & 1 & $0.65 \pm 0.98$ & $0.01-0.02$ & $\mathrm{Z}=-3.20, \mathrm{P}=0.001$ \\
Sleep Duration & $1.17 \pm 1.14$ & 1 & $0.73 \pm 0.96$ & $0.04-0.05$ & $\mathrm{Z}=-2.07, \mathrm{P}=0.03$ \\
Sleep Efficiency & $0.95 \pm 1.22$ & 0 & $0.60 \pm 0.83$ & $0.23-0.25$ & $\mathrm{Z}=-1.24, \mathrm{P}=0.21$ \\
Sleep Disturbances & $30.91 \pm 0.51$ & 1 & $0.86 \pm 0.54$ & $1.00-1.00$ & $\mathrm{Z}=-0.33, \mathrm{P}=0.73$ \\
Use of sLeep Medication & $0.69 \pm 1.25$ & 0 & $0.47 \pm 1.08$ & $0.24-0.25$ & $\mathrm{Z}=-1.63, \mathrm{P}=0.10$ \\
Day Time Dysfunction & $0.26 \pm 0.54$ & 0 & $0.04 \pm 0.20$ & $0.12-0.13$ & $\mathrm{Z}=-1.89, \mathrm{P}=0.05$ \\
Total Score & $6.08 \pm 5.27$ & 4 & $3.91 \pm 4.04$ & $0.007-0.01$ & $\mathrm{Z}=-2.57, \mathrm{P}=0.01$ \\
\hline
\end{tabular}

a Abbreviations: CI, confidence interval; SD, standard deviation. 
Valizadeh L et al.

In the reflexology group, the comparison of the scores of the components of the questionnaires before and after the intervention showed that the intervention was effective on two components of subjective sleep quality and delays in falling sleep (Table 2 ). In the foot bath group, the intervention was effective in all the components except sufficient sleep, and using sleeping drugs (Table 3 ). In the control group, the intervention was not effective in any of the components of the questionnaire (Table 4).

The total score changes among the three reflexology, foot bath, and control groups were statistically significant $(\mathrm{P}=0.01)$. Comparing the score changes of the components of sleep quality showed that the second and third parts of the questionnaire, delay in falling sleep ( $P$ $=0.03$ ) and duration of sleep $(P=0.09)$, had statistically significant differences (Table 5).

Comparing the score changes of quality of sleep between the reflexology and foot bath groups showed that there was no significant difference in none of the components and the total score $(P=0.09)$ (Table 6).

Table 3. Mean Scores Before and After the Intervention, and Confidence Interval Changes in Sleep Quality of the Elderly in Foot Bath Group.

\begin{tabular}{lccccc}
\hline Components of Questionnaire & Before Intervention & \multicolumn{2}{c}{ After Intervention } & \multicolumn{2}{c}{ Statistical Indicators } \\
\cline { 2 - 6 } & Mean \pm SD & Median & Mean \pm SD & CI 95\% for Difference & P Wilcoxon \\
\hline Subjective Sleep Quality & $1 \pm 0.67$ & 1 & $0.60 \pm 0.58$ & $0.00,0.06$ & $\mathrm{Z}=-2.49, \mathrm{P}=0.01$ \\
Sleep Latency & $1.39 \pm 1.07$ & 1 & $0.47 \pm 0.89$ & $0.00,0.06$ & $\mathrm{Z}=-3.53, \mathrm{P}=0.001$ \\
Sleep Duration & $1.52 \pm 1.03$ & 2 & $0.78 \pm 0.90$ & $0.00,0.06$ & $\mathrm{Z}=-2.91, \mathrm{P}=0.004$ \\
Sleep Efficiency & $1.04 \pm 1.33$ & 0 & $0.60 \pm 0.98$ & $0.03,0.22$ & $\mathrm{Z}=-1.68, \mathrm{P}=0.09$ \\
Sleep Disturbances & $1.17 \pm 0.38$ & 1 & $0.78 \pm 0.51$ & $0.00,0.06$ & $\mathrm{Z}=-2.27, \mathrm{P}=0.007$ \\
Use of Sleep Medication & $1.13 \pm 1.42$ & 0 & $0.73 \pm 1.28$ & $0.06,0.28$ & $\mathrm{Z}=-1.65, \mathrm{P}=0.09$ \\
Day Time Dysfunction & $0.34 \pm 0.48$ & 0 & $0.13 \pm 0.34$ & $0.00,0.10$ & $\mathrm{Z}=-2.23, \mathrm{P}=0.02$ \\
Total Score & $7.30 \pm 0.68$ & 8 & $4.13 \pm 3.57$ & $0.00,0.06$ & $\mathrm{Z}=-4.12, \mathrm{P}=0.001$ \\
\hline
\end{tabular}

Table 4. Mean Score Before and After the Intervention, and Sleep Quality Changes of the Elderly in the Control Group

\begin{tabular}{lccccc}
\hline Components of Questionnaire & Before Intervention & \multicolumn{2}{c}{ After Intervention } & \multicolumn{2}{c}{ Statistical Indicators } \\
\cline { 2 - 6 } & Mean \pm SD & Median & Mean \pm SD & CI 95\% for Difference & P Wilcoxon \\
\hline Subjective Sleep Quality & $0.91 \pm 0.51$ & 1 & $0.73 \pm 0.54$ & $0.13,0.38$ & $\mathrm{Z}=-1.63, \mathrm{P}=0.10$ \\
Sleep Latency & $0.95 \pm 1.06$ & 1 & $0.69 \pm 1.06$ & $0.11,0.36$ & $\mathrm{Z}=-1.60, \mathrm{P}=0.10$ \\
Sleep Duration & $0.82 \pm 0.98$ & 1 & $0.91 \pm 0.99$ & $0.63,0.88$ & $\mathrm{Z}=-0.36, \mathrm{P}=0.71$ \\
Sleep Efficiency & $0.56 \pm 1.03$ & 0 & $0.39 \pm 0.78$ & $0.35,0.64$ & $\mathrm{Z}=-0.69, \mathrm{P}=0.49$ \\
Sleep Disturbances & $1.04 \pm 0.20$ & 1 & $0.91 \pm 0.41$ & $0.21,0.48$ & $\mathrm{Z}=-1.34, \mathrm{P}=018$ \\
Use of Sleep Medication & $1.13 \pm 1.45$ & 0 & $0.73 \pm 1.28$ & $0.21,0.48$ & $\mathrm{Z}=-1.34, \mathrm{P}=018$ \\
Day Time Dysfunction & $0.30 \pm 0.63$ & 0 & $0.26 \pm 0.54$ & $0.93,1.00$ & $\mathrm{Z}=-0.33, \mathrm{P}=0.33$ \\
Total Score & $4.69 \pm 0.51$ & 6 & $5.69 \pm 3.08$ & $0.08,0.31$ & $\mathrm{Z}=-1.46, \mathrm{P}=0.14$ \\
\hline
\end{tabular}

Table 5. Comparing the Score Changes of Sleep Quality Among Reflexology, Foot Bath and Control Groups Using the Kruskal-Wallis Test $^{\mathrm{a}}$

\begin{tabular}{|c|c|c|c|c|}
\hline \multirow[t]{2}{*}{ Component of Questionnaire } & Reflexology Group b & Foot Bath Group b & Control Group b & \multirow[t]{2}{*}{ Statistical Indicators } \\
\hline & Mean Rank & Mean Rank & Mean Rank & \\
\hline Subjective Sleep Quality & 36.63 & 25.52 & 21.48 & chi-square $=1.62, \mathrm{df}=2, \mathrm{P}=0.44$ \\
\hline Sleep Latency & 34.33 & 28.09 & 18.91 & chi-square $=6.98, \mathrm{df}=2, \mathrm{P}=0.03$ \\
\hline Sleep Duration & 37.78 & 28.63 & 18.37 & chi-square $=9.13, \mathrm{df}=2, \mathrm{P}=0.009$ \\
\hline Sleep Efficiency & 35.74 & 25.02 & 21.98 & chi-square $=0.83, \mathrm{df}=2, \mathrm{P}=0.65$ \\
\hline Sleep Disturbances & 31.33 & 25.91 & 21.09 & chi-square $=3.79, \mathrm{df}=2, \mathrm{P}=0.15$ \\
\hline Use of Sleep Medication & 34.59 & 23.43 & 23.58 & chi-square $=0.98, \mathrm{df}=2, \mathrm{P}=0.98$ \\
\hline Day Time Dysfunction & 36.41 & $25 / 67$ & 21.33 & chi-square $=2.69, \mathrm{df}=2, \mathrm{P}=0.25$ \\
\hline Total Score & 33.87 & $29 / 48$ & 17.58 & chi-square $=8.89, \mathrm{df}=2, \mathrm{P}=0.01$ \\
\hline
\end{tabular}

\footnotetext{
a Abbreviation: df, degree of freedom.

$\mathrm{b}_{(\mathrm{n}=23) \text {. }}$
} 
Valizadeh L et al.

\begin{tabular}{|c|c|c|c|}
\hline \multirow[t]{2}{*}{ Component of Questionnaire } & Reflexology Group ${ }^{a}$ & Foot Bath Group ${ }^{a}$ & \multirow[t]{2}{*}{ Statistical Indicators } \\
\hline & Mean Rank & Mean Rank & \\
\hline Subjective Sleep Quality & 23.39 & 23.61 & Mann-Whitney $\mathrm{U}=262.00, \mathrm{Z}=-0.06, \mathrm{P}=0.95$ \\
\hline Sleep Latency & 20.61 & 26.39 & Mann-Whitney $\mathrm{U}=198.00, \mathrm{Z}=-1.59, \mathrm{P}=0.11$ \\
\hline Sleep Duration & 22.02 & 24.98 & Mann-Whitney $\mathrm{U}=230.50, \mathrm{Z}=-0.79, \mathrm{P}=0.42$ \\
\hline Sleep Efficiency & 23.13 & 23.87 & Mann-Whitney $\mathrm{U}=256.00, \mathrm{Z}=-0.21, \mathrm{P}=0.83$ \\
\hline Sleep Disturbances & 20.59 & 26.41 & Mann-Whitney $U=197.50, Z=-1.72, P=0.08$ \\
\hline Use of Sleep Medication & 23.33 & 23.67 & Mann-Whitney $\mathrm{U}=260.50, \mathrm{Z}=-0.13, \mathrm{P}=0.89$ \\
\hline Day Time Dysfunction & 23.11 & 23.89 & Mann-Whitney $U=255.50, Z=-0.28, P=0.77$ \\
\hline Total Score & 26.78 & 20.22 & Mann-Whitney $\mathrm{U}=189.00, \mathrm{Z}=-1.67, \mathrm{P}=0.09$ \\
\hline
\end{tabular}

$\mathrm{a}(\mathrm{n}=23)$.

Table 7. Comparison of Sleep Pattern in Reflexology, Foot Bath and Control Groups Using the chi-Square Test

\begin{tabular}{|c|c|c|c|c|}
\hline \multirow[t]{2}{*}{ Groups } & \multicolumn{2}{|c|}{ Before } & \multicolumn{2}{|c|}{ After } \\
\hline & Sleep Disorder ${ }^{a}$ & Lack of Sleep Disorder ${ }^{a}$ & Sleep Disorder ${ }^{a}$ & Lack of Sleep Disorder $^{a}$ \\
\hline Reflexology Group & $11(47.80)$ & $12(52.20)$ & $5(21.70)$ & $18(78.3)$ \\
\hline Foot Bath Group b & $16(69.60)$ & $7(30.40)$ & $9(39.10)$ & $14(60.90)$ \\
\hline Control Group b & $13(56.50)$ & $10(43.50)$ & $11(47.80)$ & $12(52.2)$ \\
\hline Statistical Indicators & \multicolumn{2}{|c|}{ Chi-Square $=5.23, \mathrm{df}=1, \mathrm{P}=0.02$} & \multicolumn{2}{|c|}{ Chi-Square $=1.75, \mathrm{df}=1, \mathrm{P}=0.18$} \\
\hline
\end{tabular}

$\mathrm{a}_{\text {Values are represented No. (\%). }}$

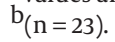

Table 7 shows the frequency and percentage of sleep disorders in the elderly in division of the three groups. The differences in the percentage of the elderly with sleep disorders before and after the intervention were $26 \%$ in the reflexology group, $30 \%$ in the foot bath group, and $8 \%$ in the control group. In other words, the intervention of reflexology and foot bath had caused purely $18 \%$ and $22 \%$ reduction in the prevalence of sleep disorders in the elderly. This reduction is clinically significant and important.

Moreover, there was no statistically significant difference among the three groups in terms of sleep disorder before the intervention ( $\mathrm{P}=0.18)$. Nevertheless, after intervention there were statistically significant differences between the three groups $(\mathrm{P}=0.02)$.

\section{Discussion}

Comparing the sleep quality scores among the three groups regarding the components of the PSQI questionnaire showed that foot bath intervention in all the components except the fourth and sixth component (sufficient sleep and using sleeping drugs) provided a statistically significant improvement; while in the reflexology group, two components of the questionnaire, subjective quality of sleep and delay in falling sleep, had significant improvement. In the control group, no significant differences were observed between the components. The score changes of the quality of sleep among the three groups showed that the most changes were related to the second and third components, delay in falling sleep and duration of sleep. Total score changes among the three groups was statistically significant.

Regarding reflexology, the clinical study of Asltoghiri and Ghodsi in Iran on evaluating the effect of reflexology on sleep quality in menopausal women (22), and the clinical study of Li et al. in Taiwan on evaluating the effectiveness of reflexology on improving sleep quality in postpartum women with sleep disorder (23), was consistent with the findings of the present study. In a systematic review of Yeung et al. on the effect of reflexology on sleep quality, it was a safe and effective intervention on insomnia; they suggested more accurate studies (17). These findings were consistent with the present study.

Regarding foot bath intervention, Yang et al. study on sleep and fatigue in patients with genital cancer undergoing chemotherapy (24), Sung et al. study on sleep of healthy women (25), were consistent with the present study but were in conflict with a crossover study of Liao et al. on the quality of sleep of elderly (16).

Yeung et al. (17) systematically review five clinical trials on the effectiveness of reflexology and other effective methods of dealing with insomnia. Zhao and Cao $(26,27)$ showed that reflexology compared with routine care, significantly reduced sleep disorders. Gong et al. (28) study did not show any significant differences between the effects of reflexology and alprazolam and Hughes et al. (29) study did not show any significant differences be- 
Valizadeh L et al.

tween reflexology, acupressure and music therapy. Jiang (30) study showed that reflexology compared to hypnosis significantly reduced sleep disorder. In the present study, there was no statistically significant difference between reflexology and foot bath.

According to the findings of this study, both interventions improved the quality of sleep in two separate aspects; therefore, both methods could be recommended as consolidations in nondrug treatment of insomnia in the elderly. It should be noted that foot bath intervention is an easy and safe intervention, and can be easily applicable by the elderly themselves; however, reflexology is an intervention that should be carried out by a nurse or another person. Therefore, foot bath intervention in terms of cost and effectiveness is more preferred than reflexology.

Since the present study was conducted on both groups of the elderly with and without sleep disorder, it is recommended that future studies be conducted on elderly with sleep disorder. In addition, according to the results of the study as well as the difficulties and restrictions, it is suggested that in future studies, both polysomnographic recordings and questionnaire should be comparably used. Besides, a similar study should be performed on elderly women.

Based on the results of this study, reflexology and foot bath are effective on the sleep quality of the elderly and improve quality of sleep. However, there was no statistically significant difference between the two interventions. Therefore, it can be said that between foot bath and reflexology, there is no difference regarding impact on sleep quality of the elderly, and the use of both methods separately or a combination of them can be effective. According to the findings, it is recommended that training non-drug methods such as reflexology and foot bath be included in the elderly health programs.

In this study, the researchers had limited access to the elderly in Tabriz City; therefore, it is recommended that future research be conducted in a higher number of health centers.

As a strong point, according to our knowledge, there is no study similar to the present study.

\section{Acknowledgments}

This study was approved and supported regarding financial and ethical aspects by Tabriz University of Medical Sciences. Appreciation goes to the research deputy, the healthcare personnel of the Monempour health center in Tabriz, and all the elderly participants who helped us in conducting this research.

\section{Footnotes}

Authors' Contributions:Leila Valizadeh, Alehe Sayyedrasooli, and Khadijeh Nasiri participated in design and data collection and writing of the manuscript. Vahid Zamanazadeh contributed to data analysis. All of them have given final approval of the version submitted for publication.

Funding/Support:This study was financially supported by Tabriz University of Medical Sciences.

\section{References}

1. Coats AJ. Life, quality of life and choice in an ageing society. Int $J$ Cardiol. 2001;78(1):1-3. [PubMed: 11259806]

2. Wu ZH, Rudkin L. Social contact, socioeconomic status, and the health status of older Malaysians. Gerontologist. 2000;40(2):22834. [PubMed: 10820926]

3. Statistical Centre of Iran. Available from: Census of population and housing in 2006 \& 2011: Tehran: Presidency for I.R.I Vice-Presidency for Strategic Planning and Supervision. 2012. Available from: http:/ www.amar.org.ir/Default.aspx?tabid=1485/.

4. Li J, Yao YS, Dong Q, Dong YH, Liu JJ, Yang LS, et al. Characterization and factors associated with sleep quality among rural elderly in China. Arch Gerontol Geriatr. 2013;56(1):237-43. doi: 10.1016/j. archger.2012.08.002. [PubMed:22906471]

5. Amagai Y, Ishikawa S, Gotoh T, Kayaba K, Nakamura Y, Kajii E. Sleep duration and incidence of cardiovascular events in a Japanese population: the Jichi Medical School cohort study. J Epidemiol. 2010;20(2):106-10. [PubMed: 20009370]

6. Qiu L, Sautter J, Liu Y, Gu D. Age and gender differences in linkages of sleep with subsequent mortality and health among very old Chinese. Sleep Med. 2011;12(10):1008-17. doi: 10.1016/j. sleep.2011.04.014. [PubMed: 22036598]

7. Chan MF, Chan EA, Mok E. Effects of music on depression and sleep quality in elderly people: A randomised controlled trial. Complement Ther Med. 2010;18(3-4):150-9. doi: 10.1016/j. ctim.2010.02.004. [PubMed: 20688261]

8. Ford DE, Kamerow DB. Epidemiologic study of sleep disturbances and psychiatric disorders. An opportunity for prevention? JAMA. 1989;262(11):1479-84. [PubMed: 2769898]

9. Eser I, Khorshid L, Cinar S. Sleep quality of older adults in nursing homes in Turkey: enhancing the quality of sleep improves quality of life. J Gerontol Nurs. 2007;33(10):42-9. [PubMed: 17955737]

10. Nobahar M, Vafaaee A. Elderly sleep disturbances and management [in Persian]. GERIATR NURS. 2007;2(4):263-8.

11. Zilli I, Ficca G, Salzarulo P. Factors involved in sleep satisfaction in the elderly. Sleep Med. 2009;10(2):233-9. doi: 10.1016/j. sleep.2008.01.004. [PubMed:18387848]

12. Montgomery P, Dennis J. Physical exercise for sleep problems in adults aged 60+. Cochrane Database Syst Rev. 2002;(4):CD003404. doi:10.1002/14651858.CD003404. [PubMed:12519595]

13. Gunnarsdottir TJ, Peden-McAlpine C. Effects of reflexology on fibromyalgia symptoms: a multiple case study. Complement Ther Clin Pract. 2010;16(3):167-72. doi: 10.1016/j.ctcp.2010.01.006. [PubMed: 20621279]

14. Steenkamp E, Scrooby B, Van der Walt C. Facilitating nurses' knowledge of the utilisation of reflexology in adults with chronic diseases to enable informed health education during comprehensive nursing care: original research. Health SA Gesondheid. 2011;17(1):1-12.

15. Raymann RJ, Van Someren EJ. Diminished capability to recognize the optimal temperature for sleep initiation may contribute to poor sleep in elderly people. Sleep. 2008;31(9):1301-9. [PubMed: 18788655]

16. Liao WC, Chiu MJ, Landis CA. A warm footbath before bedtime and sleep in older Taiwanese with sleep disturbance. Res Nurs Health. 2008;31(5):514-28. doi: 10.1002/nur.20283. [PubMed: 18459154]

17. Yeung WF, Chung KF, Poon MM, Ho FY, Zhang SP, Zhang ZJ, et al Acupressure, reflexology, and auricular acupressure for insomnia: a systematic review of randomized controlled trials. Sleep Med. 2012;13(8):971-84. doi: 10.1016/j.sleep.2012.06.003. [PubMed: 22841034]

18. Goosmann L,Astrid I. Reflex foot massage points. Tehran: Nil; 2010

19. Buysse DJ, Reynolds C3, Monk TH, Berman SR, Kupfer DJ. The Pittsburgh Sleep Quality Index: a new instrument for psychi- 
atric practice and research. Psychiatry Res. 1989;28(2):193-213. [PubMed: 2748771]

20. Tzeng JI, Fu YW, Lin CC. Validity and reliability of the Taiwanese version of the Pittsburgh Sleep Quality Index in cancer patients. Int J Nurs Stud. 2012;49(1):102-8. doi:10.1016/j.ijnurstu.2011.08.004. [PubMed: 21924421]

21. Reza H, Kian N, Pouresmail Z, Masood K, Sadat Seyed Bagher M, Cheraghi MA. The effect of acupressure on quality of sleep in Iranian elderly nursing home residents. Complement Ther Clin Pract. 2010;16(2):81-5. doi: 10.1016/j.ctcp.2009.07.003. [PubMed: 20347838]

22. Asltoghiri M, Ghodsi Z. The effects of Reflexology on sleep disorder in menopausal women. 2012;31:242-6. [PubMed: 21484056]

23. Li CY, Chen SC, Li CY, Gau ML, Huang CM. Randomised controlled trial of the effectiveness of using foot reflexology to improve quality of sleep amongst Taiwanese postpartum women. Midwifery. 2011;27(2):181-6. doi: 10.1016/j.midw.2009.04.005. [PubMed: 19577829]

24. Yang HL, Chen XP, Lee KC, Fang FF, Chao YF. The effects of warmwater footbath on relieving fatigue and insomnia of the gynecologic cancer patients on chemotherapy. Cancer Nurs. 2010;33(6):454-60. doi: 10.1097/NCC.0b013e3181d761c1. [PubMed:
20562619]

25. Sung EJ, Tochihara Y. Effects of bathing and hot footbath on sleep in winter. J Physiol Anthropol Appl Human Sci. 2000;19(1):21-7. [PubMed: 10979246]

26. Zhao FM, Chen QW. Palma massage in the treatment of insomnia in elder ly inpatients [in Chinese]. Chin J Clin Rehabil. 2006;10:16-7.

27. Cao XF, Li SF. Prevention of insomnia treated by foot acupressure. Chin Med Modern Distance Edu China. 2009;7:168-9.

28. Gong YL, Zhang YB, Han C, Jiang YY, Li Y, Chen SC, et al. [Clinical observation on therapeutic effect of the pressing plantar reflex area with wooden needle for treatment of patients with insomnia]. Zhongguo Zhen Jiu. 2009;29(11):935-7. [PubMed: 19994698

29. Hughes CM, McCullough CA, Bradbury I, Boyde C, Hume D, Yuan J, et al. Acupuncture and reflexology for insomnia: a feasibility study. Acupunct Med. 2009;27(4):163-8. doi: 10.1136/ aim.2009.000760. [PubMed:19942722]

30. Jiang BC. Efficacy observation of 128 cases of insomnia treated by foot reflexology [in Chinese]. Jiangsu Foot Reflexology Research Conference; Jiangsu. 1999. 